\title{
Identificação das classes metabólicas secundárias em extratos etanólicos foliares de Byrsonima verbascifolia, Cardiopetalum calophyllum, Curatella americana e Qualea grandiflora
}

Antonio Carlos Pereira de Menezes Filho, Carlos Frederico de Souza Castro

Instituto Federal de Educação, Ciência e Tecnologia Goiano - IF Goiano, GO. E-mail: astronomoamadorgoias@gmail.com

\section{Resumo}

O Cerrado representa um banco fitoquímico de grande importância para a humanidade. O objetivo deste estudo foi identificar através da prospecção fitoquímica, os principais compostos químicos presentes nos extratos foliares de Byrsonima verbascifolia, Cardiopetalum calophyllum, Curatella americana e Qualea grandiflora. Neste estudo, foram coletadas folhas das espécies em área de preservação permanente (APP) no município de Rio Verde, GO. Os extratos foliares etanólicos foram avaliados quanto à presença ou não dos principais fitocompostos: ácidos orgânicos, açúcares redutores, alcalóides, antraquinonas, catequinas, cumarinas, depsídeos, depsidonas, ligações olefínicas, fenóis, flavonóides, glicosídeos cardiotônicos, polissacarídeos, purinas, saponinas e taninos. Exceto para grupos olefínicos, polissacarídicos e purínicos, foram observados resultados positivos para a maioria das classes metabólicas secundárias. A pesquisa preliminar dos extratos foliares etanólicos destas quatro espécies, possibilita uma prévia avaliação sobre suas características fitoquímicas devendo ainda ser avaliadas quanto aos seus teores e compostos majoritários para que se possam ser utilizadas como medicamentos fitoterápicos ou sintetização industrial. Palavras-chave: propriedades fitoquímicas; extrato foliar; fitocompostos.

Identification of secondary metabolites classes in leaf ethanolic extracts of Byrsonima verbascifolia, Cardiopetalum calophyllum, Curatella americana and Qualea grandiflora

\begin{abstract}
The Cerrado represents a phytochemical bank of great importance for humanity. The objective of this study was to identify through phytochemical prospecting, the main chemical compounds present in the leaf extracts of Byrsonima verbascifolia, Cardiopetalum calophyllum, Curatella americana and Qualea grandiflora. In this study, leaves of the species were collected in a permanent preservation area (APP) in the city of Rio Verde, State of Goiás. Ethanolic foliar extracts for the presence or absence of the main phytocomponents: organic acids, reducing sugars, alkaloids, anthraquinones, catechins, coumarins, depsidones, olefinic bonds, phenols, flavonoids, cardiotonic glycosides, polysaccharides, purines, saponins and tannins were evaluated. Except for olefin, polysaccharide and purine groups, positive results were observed for most of the secondary metabolic classes. Preliminary research on the ethanolic foliar extracts of these four species makes possible a preliminary evaluation about their phytochemical characteristics and should be evaluated for their contents and major compounds so that they can be used as herbal medicines or industrial synthesis.
\end{abstract}

Keywords: phytochemical properties; foliar extracts; phyto-compounds. 


\section{Introdução}

O Cerrado é o segundo maior domínio fitogeográfico brasileiro com área de 2 milhões de $\mathrm{Km}^{2}$, apresentando uma grande variedade de gêneros botânicos, sendo composto por aproximadamente 12.500 espécies de angiospermas, onde entorno de 4.400 são endêmicas desse bioma (BUENO et al., 2018; ZAPPI et al., 2015; MENDONÇA et al., 2008; MYERS et al., 2000). Várias espécies vegetais extraídas desse bioma são utilizadas pela população no preparo de infusões, pomadas, licores e "garrafadas" utilizadas para sanar os problemas causados pelas doenças.

A população há milênios já utilizavam as plantas como meio terapêutico para cura ou prevenção de doenças, más ainda pouco se conhece sobre os efeitos e ações que a maioria desses vegetais apresenta, carecendo ainda hoje, de estudos sobre as reais ações terapêuticas proporcionadas (DE BONA et al., 2012). Todo composto vegetal apresenta algum efeito nocivo quando ingerido ou mesmo utilizado em meio tópico sem estudos prévios sobre a dosagem necessária, sendo importante uma prévia avaliação da dose letal $\left(D_{50}\right)$. Com isso ainda se conhece pouco sobre a constituição química dos vegetais que coabitam as variantes do Cerrado brasileiro.

A espécie Byrsonima verbascifolia Rich. ex A. Juss. é utilizada como planta medicinal e na gastronomia brasileira devido às propriedades farmacológicas de seus metabólitos secundários. O gênero Byrsonima é o mais representativo da família Malpighiaceae com 1.300 espécies apresentando ampla distribuição neotropical (SALDANHA; SOARES, 2015; DAVIS; ANDERSON, 2010). No Brasil ocorrem cerca de 51 espécies Byrsonima (MAMEDE; FRANCENER, 2015), sendo conhecidas popularmente por muricis, muricicascudo, murici de anta, entre outros nomes. Seu uso medicinal apresenta ações, antisséptica, antimicrobiana, anti-hemorrágica, cicatrizante, anti-inflamatória e com atividade alelopática (SALDANHA; SOARES, 2015).

A espécie Cardiopetalum calophyllum Schltdl. pertence à família Annonaceae que apresenta em torno de 2.500 espécies, distribuídas em 135 gêneros pantropicais. No Brasil a família tem cerca de 386 espécies e 29 gêneros; para o domínio Cerrado são descritas 10 gêneros e 47 espécies distribuídas nas diferentes fitofisionomias (XAVIER et al., 2016; LOPES; MELLO-SILVA, 2014). Algumas comunidades humanas utilizam a $C$. calophyllum para tratar doenças como bronquite, sinusite e processos inflamatórios, e atividades leishmanicida e larvicida contra Aedis aegiptis (XAVIER et al., 2016; COSTA et al., 2013; VILA-VERDE et al., 2003).

A família Dilleniaceae possui 11 gêneros com ampla distribuição pantropical, sendo que Curatella é monoespecífico, constituído da espécie $C$. americana $\mathrm{L}$. presente desde o México até o Brasil, colonizando as mais variadas fitofisionomias do Cerrado (FRAGA; PAULASOUZA, 2015; SOARES et al., 2005), conhecida popularmente como lixeira, devido suas folhas serem ásperas, é empregada na medicina popular (CORRÊA, 1984), e apresenta ação antiinflamatória, analgésica e antiúlcera (HENRIQUES; ALMEIDA, 2013), e antifúngica (TOLEDO et al., 2015). No uso farmacêutico atual o extrato foliar é empregado em cremes para uso tópico (QUEIROZ; SOUSA, 2017).

A espécie Qualea grandiflora Mart. pertence à família Vochysiaceae, endêmica da América do Sul, nativa do Brasil, encontrada apenas em Cerrado lato sensu. Esta espécie é conhecida popularmente por pau-terra da folha larga ou pau-terra-grande (AYRES et al., 2008; CORRÊA, 1984). As cascas e folhas possuem uso fitoterapêutico popular com ação preventiva de lesões na mucosa gástrica, e atividade antibacteriana no extrato da casca (HIRUMALIMA et al., 2006), e para o extrato foliar já foram identificadas ações analgésica, depressora do sistema nervoso central, anticonvulsivante, antioxidante, antidiarreico e antibacteriano conforme Lima Neto et al. (2015) e Gaspi et al. (2006). Além de ser uma planta hiperacumuladora de Al muito presente nos solos do Cerrado (ANDRADE, 2007).

A fitoterapia é considerada por muitos a forma de chegar à cura, aliviar as dores, infecções e muitas das vezes tratar com o mínimo de gasto financeiro, principalmente em populações de baixo poder aquisitivo, diminuindo o gasto de grandes valores ao adquirir um medicamento sintético (SILVA; FARIA, 2014). De acordo com Mota et al. (2014) e Guerra e Nodari (2007) afirmam que a as classes dos fitoterápicos e fitofármacos representam $25 \%$ dos medicamentos prescritos pelos médicos nos países desenvolvidos e $80 \%$ em desenvolvimento.

É de extrema importância o estudo fitoquímico para o conhecimento dos compostos presentes nas várias partes constituintes dos 
vegetais, otimizando os de isolamento e quantificação dos compostos específicos para a produção de novos fitoterápicos.

Os compostos metabólitos secundários apresentam em grandes quantidades, possuindo estruturas químicas complexas, baixo peso molecular e alta atividade biológica sendo diferentes dos observados pelos metabólitos primários que possuem teores mais baixos nos vegetais (LIMA; SILVA, 2016).

O presente estudo teve como objetivo a prospecção dos extratos etanólicos de folhas das espécies vegetais $B$. verbascifolia, $C$. calophyllum, $C$. americana e $Q$. grandiflora com vistas à identificação das classes de metabólitos secundários existentes.

\section{Material e Métodos}

Amostras das folhas do estudo foram coletadas em uma área de Cerrado pertencente à Universidade de Rio Verde-GO com as seguintes coordenadas geográficas $\left(17^{\circ} 47^{\prime} 09.4^{\prime \prime} \mathrm{S}\right.$ $50^{\circ} 58^{\prime} 00.6^{\prime \prime} \mathrm{W}$ ); as espécies foram herborizadas e tombadas no herbário do IF Goiano, Campus Rio Verde, onde ocorreu a determinação correta tratando-se das espécies Cardiopetalum calophyllum, Curatela americana, Byrsonima verbascifolia e Qualea grandiflora. As amostras receberam número de registro respectivamente (HRV: 10054, 10037, 958 e 10077). Após esses trâmites, as folhas foram coletadas no mês de outubro de 2018, nas primeiras da manhã, armazenadas separadamente em embalagens plásticas de polietileno transparente e levadas para o laboratório de Química Tecnológica no Instituto Federal Goiano, Campus Rio Verde-GO. Imediatamente lavadas em água corrente e após secas em papel toalha. O material foi triturado separadamente em liquidificador doméstico até obtenção de um triturado homogêneo. Foram pesadas $100 \mathrm{~g}$ desse triturado e realizada a extração utilizando $250 \mathrm{~mL}$ de álcool etílico $95 \%$, deixando macerar por sete dias ao abrigo de luz e calor. Após esse tempo, os extratos foram filtrados em papel de filtro qualitativo e o sobrenadante foi centrifugado em tubos falcon de $50 \mathrm{~mL}$ a $3000 \mathrm{rpm}$ por 15 minutos. Em seguida o sobrenadante foi armazenado e mantidos em frascos de cor âmbar na geladeira a $8{ }^{\circ} \mathrm{C}$ até análises.

Para as análises qualitativas de ácidos orgânicos, açúcares redutores (AR), alcaloides, catequinas, fenóis, taninos, flavonoides, polissacarídeos, depsídios e depsidonas, e purinas foram realizadas conforme proposto por Gomes et al. (2017); para determinação de duplas ligações olefínicas seguiu conforme descrito por Menezes Filho e Castro (2019), para determinação qualitativa de cumarinas foi realizada conforme proposto por Silva e Lima (2016); para determinação da presença de saponinas, seguiu de acordo com Kloss et al. (2016).

\section{Resultados e Discussões}

As classes de compostos fitoquímicos encontrados nos extratos foram: ácidos orgânicos, açúcares redutores, alcaloides, antraquinonas, catequinas, cumarinas, depsídeos e depsidonas, fenóis, flavonoides, glicosídeos cardíacos, saponinas e taninos pirogálicos e catéquicos, entretanto não foram encontradas as seguintes classes de compostos: ligações olefínicas, polissacarídicos e purinas em nenhum das espécies vegetais estudadas (Tabela 1 ). 
Tabela 1. Perfil fitoquímico qualitativo dos extratos etanólicos foliares de Byrsonima verbascifolia, Cardiopetalum calophyllum, Curatella americana e Qualea grandiflora.

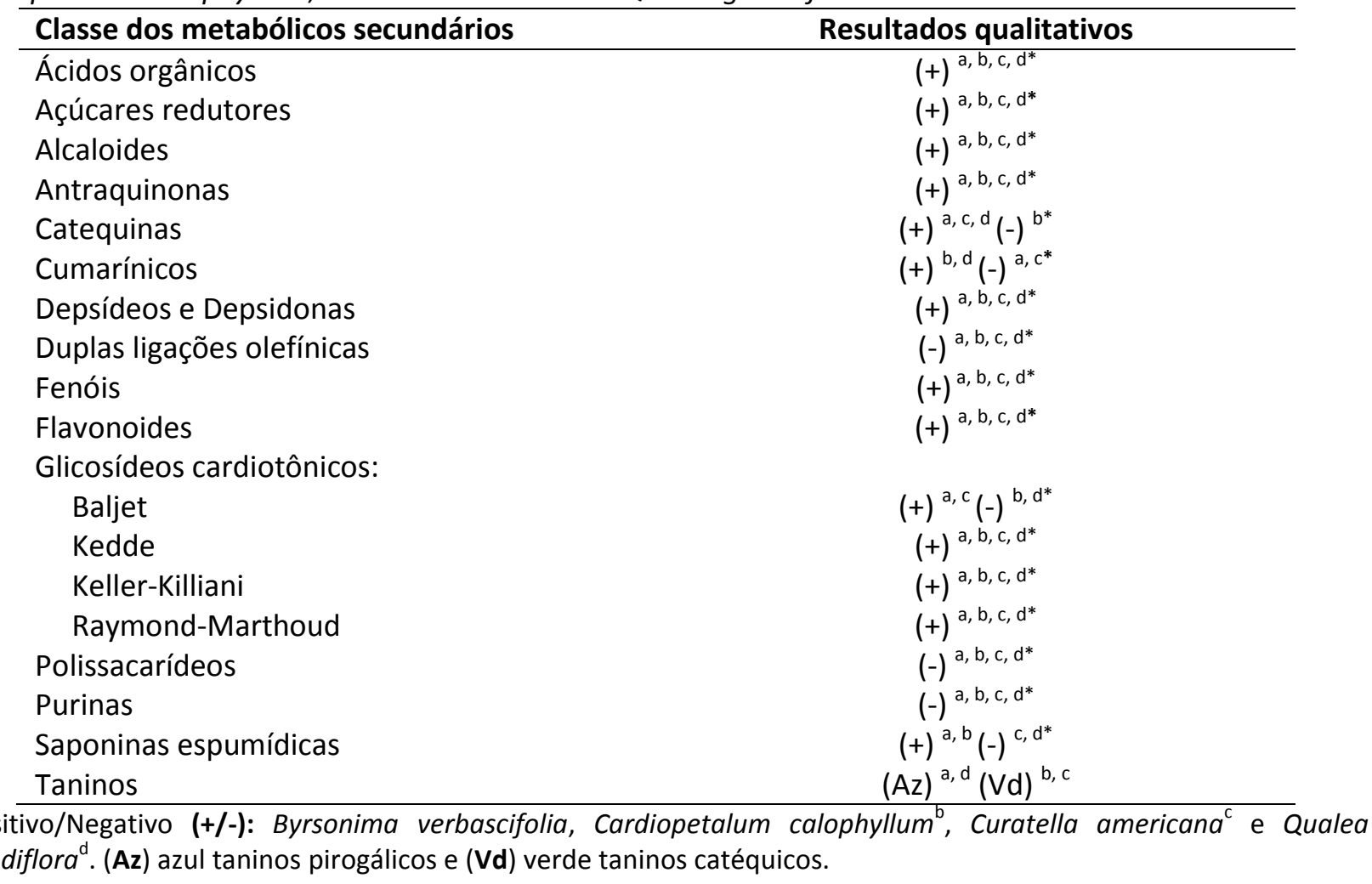

A presença de grupos químicos de grande importância sobre o potencial fitoterápico como açúcares, alcaloides, fenóis, flavonóides e taninos como observado na Tabela 1, pode ser indicativo de novas potencialidades farmacológicas. Também, foi identificada a presença de ácidos orgânicos nos extratos foliares.

Ácidos orgânicos também foram observados por Guilhion-Simplicio e Pereira (2011) para o extrato de B. verbascifolia. Estudo realizado por Henriques e Almeida (2013) avaliando o extrato foliar de C. americana também encontraram resultado positivo para ácidos orgânicos, corroborando com o resultado obtido para esta mesma espécie avaliada neste estudo. Ayres et al. (2008) avaliaram o extrato etanólico foliar de $Q$. grandiflora, onde encontraram quantitativos expressos em ácidos ursólico e oleanólico.

Os ácidos orgânicos são um dos grupos de metabólitos secundários mais expressivos nos vegetais, sendo encontrados no interior dos vacúolos; os estudos têm demonstrado ações antibacteriana e antifúngica, sendo também utilizados na indústria de alimentos como aditivos conservadores aumentando o tempo de vida de prateleira (GOMES et al., 2017).

Neste estudo, foram observados resultados positivos para o grupo de açúcares redutores em todos os extratos avaliados. Henriques e Almeida (2013) avaliaram a presença de açúcares no extrato foliar etanólico de $C$. americana onde obtiveram resultado positivo. Este grupo de compostos também foi avaliado por Randau et al. (2004) avaliando outro grupo vegetal onde encontraram traços de açúcares redutores em Croton rhamnifolius H. B. K. e em Croton rhamnifolioides Pax \& Hoffm.

Os açúcares redutores possuem funções como agente antioxidante prevenindo a ação da radiação UV incididas diretamente em plantas a pleno sol e também em animais (HENRIQUES; ALMEIDA, 2013).

O grupo dos alcalóides foi observado em todos os extratos nesta pesquisa. Gomes et al. (2016) encontraram compostos alcaloides em extratos brutos hexânicos, aceto etílicos e metanólicos das folhas de Cinnamomum zeylanicum Blume. Oliveira et al. (2014) avaliaram extratos em diferentes solventes extratores (etanólico, hexânico, clorofórmico e aceto etílico) 
em folhas de Psychotria fractistipula L. B. Sm., Klein \& Delprete onde apenas foi constatado através do teste de cromatografia em camada delgada (CCD) a presença positiva para o extrato foliar clorofórmico.

Já Silva et al. (2010), avaliaram a prospecção fitoquímica foliar para alcalóides de Terminalia fagifolia Mart. \& Zucc., Copaifera langsdorff Desf., Mouriri elliptica Mart., Hymathatus obouvatus Mart. Arg., Magonia pubenscens A. St. Hill., Astronium franxinifolium Sehott., Agonandra brasiliensis Miers., Bowdichia virgiloides H. B. \& K., Hancornia speciosa Gomez, Platymenta reticulata Benth., Stryphnodendron coriaceum Benth., Parkia platycephala Benth., Sclerolobium paniculatum Vog. e Alibertia edulis (Rich.) A. Rich. ex DC. positivo, e negativo para Protium heptaphyllum (Aubl.) March., Myracrodruon urundeuva Fr. All., Annona coriacea Mart.. Brito et al. (2008) afirmaram que o grupo dos alcalóides apresentam ação antihipertensiva, antitumoral e anti-inflamatória. Já Vizzotto et al. (2010) argumenta que os alcaloides possuem a função de proteção para o vegetal contra ataque de fitopatógenos e por herbivoria, a cafeína por exemplo, é produzida pelo vegetal para inibir os animais que se alimentam de certas espécies.

Os extratos foliares avaliados
apresentaram resultados positivos para antraquinonas. Já no estudo desenvolvido por Henriques e Almeida (2013) os pesquisadores obtiveram resultado negativo avaliando o extrato etanólico foliar de C. americana para antraquinonas. Um dos possíveis motivos está embasado no stress hídrico e queimadas. Ayres et al. (2008) também encontraram compostos antraquinônicos no extrato foliar de $Q$. grandiflora. O mesmo não foi observado por Cordeiro et al. (2006) avaliando diferentes extratos em pó de Nasturtium officinale R. Br., Rosmarinus officinalis Linn., Tabebuia impetiginosa (Mart. ex DC.) Standl., Plantago major L. e em Achillea millefolium subsp. millefolium Afan. onde não encontraram compostos antraquinônicos.

O grupo das catequinas avaliados apresentaram resultados positivos para $B$. verbacifolia, C. americana e Q. grandiflora e negativo para $C$. calophyllum. Corroborando com Cecílio et al. (2012) onde também encontraram compostos catequínicos em extrato foliar de $B$. verbascifolia. Godinho et al. (2015) avaliaram extratos foliares de Anacardium humile St. Hill.,
Eugenia dysenterica Dc., Myracrodruon urundeuva Fr. All., com resultado positivo para catequina e para os extratos de Brosimum gaudichaudii Trec., Astronium fraxinifolium Schott., Solanum lycocarpum A. St. Hill. e Solanum paniculatum L. que apresentaram resultados negativos. Pinho et al. (2012) observaram resultados positivos em prospecção fitoquímica em extratos foliares hidroalcoólicos de Lippia sidoides Cham. (Alecrim) e, resultados negativos em Myracrodruon urundeuva Fr. All. (Aroeira), Stryphnodendron adstringens Mart. Coville (Barbatimão) e Cordia verbenacea DC. (Erva baleeira).

Os compostos catéquicos possuem atividade como redutor do tecido adiposo baseado no metabolismo químico dos lipídeos e com ação antiulcerogênica (GOMES et al., 2017), e ação antimutagênica (CARMINATE et al., 2014).

A reação de identificação positiva para cumarinas apresentou resultados positivos para C. calophyllum e $Q$. grandiflora, negativo para $B$. verbacifolia e $C$. americana. Ao contrário do observado neste estudo para B. verbascifolia, Cecílio et al. (2012) encontraram compostos cumarínicos para a mesma espécie. Corroborando com este estudo, Henriques e Almeida (2013) também não observaram no extrato foliar de $C$. americana a presença de cumarinas. Em outros estudos propostos por Silva e Peixoto (2013) avaliando extrato etanólico foliar de Justicia thunbergioides (Lindau) Leonard onde os pesquisadores obtiveram resultado positivo para compostos cumarínicos. E por Randau et al. (2004) onde avaliaram extratos metanólicos das folhas de $C$. rhamnifolius e $C$. rhamnifolioides e não observaram a presença de compostos cumarínicos. A comparação entre os gêneros e famílias distintas, apresentam importantes dados para comparação entre os vários grupos vegetais. Esse tipo de estudo viabiliza que seja realizado o estudo de drogas vegetais individuais ou por sinergismo promovendo a potencialização das classes fitoquímicas na promoção da saúde.

De acordo com Silva e Peixoto (2013) e Kuster e Rocha (2010), os compostos cumarínicos apresentam odor característico, onde alguns destes são utilizados como aromatizantes no processamento industrial aplicado a alimentos, na indústria de produtos de limpeza doméstica e industrial e como adjuvantes em cosméticos e produção de medicamentos com ação anticoagulante. 
Os compostos de depsídeos e depsidonas foram positivos para os quatro extratos foliares avaliados. O mesmo foi observado por Henriques e Almeida (2013) para o extrato foliar de C. americana. Cruz (2016) obteve resultado positivo para depsídios e depsidonas nos extratos foliares etanólicos de Bowdichia virgiloides Kunth. e Pterodon emarginatus Vogel. Bitencourt e Almeida (2014) não encontraram depsídeos e depsidonas no extrato foliar de Costus spicatus Jacq. Henriques e Almeida (2013) também encontraram resultados positivos para o extrato etanólico foliar de C. americana, corroborando com o resultado obtido para essa mesma espécie neste estudo. Rodrigues et al. (2009) avaliando o extrato das folhas de Senna alata L. Roxb. obtiveram resultado indeterminado para depsídeos.

De acordo com Duarte et al. (2014) os depsídeos e depsidonas são compostos fenólicos que apresentam ação antioxidante. Já Mota (2013), Micheletti et al. (2009) e Macedo et al. (2007) afirmam que estes compostos possuem ação antitumoral, antioxidante, antipirética e também promover analgesia.

Não foi observada a presença de duplas ligações olefínicas nos quatro extratos foliares avaliados neste estudo. Comparando outras espécies bem como famílias em diferentes biomas, Júnior et al. (2014) avaliaram frações diclorometano do extrato das folhas de Eugenia copacabanensis Kiaersk. do Bioma de Mata Atlântica, onde encontraram resultado positivo para carbonos olefínicos. As duplas olefínicas são capazes de formarem compostos resinosos e oleosos, podendo também apresentar aromas adocicados. A interação entre diferentes espécies e em fitofisionomias diferentes fornecem dados, compostos e ações que podem agir por sinergismo potencializando um determinado produto, com possíveis ações, fitoterápicas, alimentícias, bem como empregado em numerosos processos agrícolas, como agente larvicida, inseticida e antifúngica.

A presença de compostos fenólicos foi observada em todos os extratos foliares avaliados. O mesmo foi observado por Cecílio et al. (2012) para o extrato foliar de B. verbascifolia. Menezes et al. (2018) também encontraram compostos fenólicos no extrato foliar de $C$. calophyllum. Ao contrário deste estudo, Henriques e Almeida (2013) encontraram compostos fenólicos no extrato foliar de $C$. americana. $\mathrm{O}$ mesmo foi observado por El-Azizi et al. (1980) para o extrato foliar de C. americana. Os compostos fenólicos contribuem para o sabor, odor e composição de cores em diversos vegetais, possuindo também característica antioxidante, diminuindo as reações oxidativas envolvidas em patologias como nos mais diversos tipos de cânceres e envelhecimento precoce (DUARTE et al., 2014; SIMÕES et al., 2007).

Todas as espécies avaliadas apresentaram reação positiva para presença de flavonóides nos extratos etanólicos foliares. O mesmo foi observado por El-Azizi et al. (1980) para o extrato foliar de C. americana corroborando com este estudo. Já Henriques e Almeida (2013) não encontraram compostos flavonólicos no extrato foliar de C. americana. Estudo desenvolvido por Ayres et al. (2008) encontraram no extrato etanólico foliar de $Q$. grandiflora compostos flavonólicos, o mesmo possui atividade antioxidante.

Conforme Cushnie e Lamb (2005) os flavonóides possuem importante atividade antimicrobiana, já para Oliveira e Lima (2017) os flavonóides são usados no tratamento de problemas circulatórios, hipertensão e agindo como cofator do ácido ascórbico, Mendanha et al. (2010), afirmam que os compostos flavonólicos também possuem efeito antimutagênico.

Os compostos glicosídeos cardiotônicos foram observados na reação de Baljet com resultado positivo para $B$. verbacifolia e $C$. americana e negativo para $C$ calophyllum e $Q$. Grandiflora. Nos testes utilizando os reativos de Kedde, Keller-Killiani e Raymond-Marthoud foram encontrados neste estudo resultados positivos para todos os extratos avaliados. Oliveira e Lima (2017) avaliaram os compostos glicosídicos no extrato etanólico foliar de $B$. forficata e encontraram resultados positivos para os reativos de Keller-Killiani, Salkowski, Baljet e RaymondMarthoud e negativo para Kedde e Lieberman.

Silva e Peixoto (2013) obtiveram resultado positivo para a presença de compostos glicosídeos cardiotônicos no extrato foliar de $J$. thunbergioides. Os autores ainda discutem a ação destes compostos sobre a musculatura cardíaca sendo utilizados como drogas no tratamento de insuficiência cardíaca congestiva (ICC) e para o tratamento de choque cardiogênico (KELLY; SMITH apud RATES; BRIDI, 2010).

A prospeç̧ão fitoquímica para polissacarídeos neste estudo não apresentou resultados positivos para nenhum dos extratos 
avaliados. O mesmo foi observado por Henriques e Almeida (2013) para o extrato foliar de C. americana. Já El-Azizi et al. (1980) estudando a mesma espécie encontraram resíduos de monossacarídeos pertencentes a arabinose. Um dos principais polissacarídeos é o amido, muito utilizado na indústria de alimentos e também como biomaterial, sendo utilizado no processo de cicatrização em lesões cutâneas (SCHIRATO et al., 2006).

Neste estudo não foi observado resultados qualitativos positivos para purinas. Compostos purínicos também não foram observados por Henriques e Almeida (2013) para o extrato foliar de C. americana. Gomes et al. (2017) também não encontram esta classe de compostos no extrato etanólico foliar avaliado de N. pectinata.

De acordo com Vizzotto et al. (2010), os compostos purínicos são derivados de aminoácidos como a glicina, ácido L-aspártico e Lglutamina, possuindo estrutura cíclica com no mínimo um átomo de nitrogênio no seu anel, as purinas são amplamente utilizadas na indústria de fármacos com ação alucinógena e também como veneno.

Saponinas espumídicas foram verificadas

em B. verbacifolia e C. calophyllum. Corroborando com este estudo, Cecílio et al. (2012) também encontraram compostos saponínicos em extrato foliar de $B$. verbascifolia. Henriques e Almeida (2013) também não encontraram saponinas no extrato foliar de $C$. americana. Neste estudo também não foi observado a formação de espumas no extrato etanólico foliar de $Q$. grandiflora. Já Lima Neto et al. (2015) encontraram resultado positivo para compostos saponínicos para esta espécie. As saponinas podem ser usadas para tratamento de inflamações atribuídas a bronquite promovendo a hidratação da árvore brônquica e como agente antibacteriano (CLEMES et al., 2008; VERDI et al., 2005).

A análise de tanino apresentou resultados positivos para taninos pirogálicos em B. verbascifolia e $Q$. grandiflora e taninos catéquicos para $C$. calophyllum e $C$. americana. Cecílio et al. (2012) também verificaram a presença de compostos tanínicos em extrato foliar de B. verbascifolia. Henriques e Almeida (2013) também observaram compostos tanínicos no estrato foliar de C. americana. Ayres et al. (2008) verificaram também a presença de compostos tanínicos no extrato etanólico foliar de $Q$. grandiflora corroborando com este estudo.

Espécies vegetais ricas em compostos tânicos são utilizadas no tratamento de doenças, tais como, diarreia, processos reumáticos, hemorragias, queimaduras e como antídoto em envenenamentos (SILVA; PEIXOTO, 2013; CUNHA; ROQUE, 2010).

\section{Conclusão}

As análises fitoquímicas preliminares fornecem importantes dados sobre a presença ou não de certos compostos metabólicos de segunda ordem nos vegetais. A partir dessas análises simples e corriqueiras, podemos determinar qualitativamente a presença de compostos fitoquímicos e seguir com o isolamento desses princípios ativos para que se possam produzir novos medicamentos ou mesmo aditivos para a indústria de alimentos, como os compostos com atividade antioxidante.

Este estudo corroborou com vários outros já existentes na literatura científica avaliando as espécies, Byrsonima verbascifolia, Cardiopetalum calophyllum, Curatella americana, Qualea grandiflora. Dentre as espécies avaliadas, os compostos cujos resultados foram os mais observados, destacando as classes de ácidos orgânicos, açúcares redutores, alcaloides, antraquinonas, depsídeos e depsidonas, fenólicos, flavonóides, glicosídeos cardíacos e taninos. Assim podemos confirmar as ações terapêuticas promovidas pelas quatro espécies utilizadas como fitoterápicos pela população, pois suas ações foram confirmadas na literatura científica.

\section{Agradecimentos}

Os autores agradecem ao Instituto Federal de Educação, Ciência e Tecnologia Goiano, Campus Rio Verde; ao Laboratório de Química Tecnológica - QUITEC; aos órgãos de fomento em pesquisa CNPq, CAPES e FAPEG pela bolsa de mestrado para o primeiro autor Antonio.

\section{Referências}

ANDRADE, L. R. M. Efeito das condições edáficas na disponibilidade e acumulação de alumínio e de nutrientes em plantas nativas do Cerrado. In: XI CONGRESSO BRASILEIRO DE FISIOLOGIA VEGETAL, 19., 2007, Rio Grande do Sul. Resumos 
[...]. Rio Grande do Sul: Brazilian Journal of Plant Physiology, 2007.

AYRES, M. C. C.; ESCÓRIO, S. P.; COSTA, D. A. da.; CHAVES, M. H.; VIEIRA JÚNIOR, G. M.; CAVALHEIRO, A. J. Constituintes químicos das folhas de Qualea grandiflora: atribuição dos dados de RMN de dois flavonóides glicosilados acilados diastereoisoméricos. Revista Química Nova, v.31, n.6, p. 1481-1484, 2008.

http://dx.doi.org/10.1590/S0100$\underline{40422008000600038}$

BITENCOURT, A. P. R.; ALMEIDA, S. S. M. da. S. de. Estudo fitoquímico, toxicológico e microbiológico das folhas de Costus spicatus Jacq. Biota Amazônia, v.4, n.4, p. 75-79, 2014.

http://dx.doi.org/10.18561/2179-

5746/biotaamazonia.v4n4p75-79.

BRITO, H. O.; NORONHA, E. P.; FRANÇA, L. M.; BRITO, L. M. O.; PRADO, M. S-A. Análise da composição fitoquímica do extrato etanólico das folhas da Annona squamosa (ATA). Revista Brasileira de Farmacognosia, v.83, n.3, p. 180184, 2008.

BUENO, M. L.; Oliveira-Filho, A. T. de.; PONTARA, V.; POTT, A.; DAMASCENO-JÚNIOR, G. A. Flora arbórea do cerrado de Mato Grosso do Sul. Revista Iheringia Série Botânica, v.73, supl., p. 53-64, 2018. https://doi.org/10.21826/2446$\underline{8231201873 s 53}$

CARMINATE, B.; CARVALHOS, C. A. de.; PACHECO, T. F.; NATALLI, V. D.; SILVA, M. B. de. Investigação antibacteriana in vitro de extratos etanólicos das folhas e cascas de Cedrela fissilis Vell. Ciência e Natura, v.36, Ed. Especial, p. 335-340, 2014. http://doi.org/10.5902/2179460X13234

CECÍlIO, A. B.; FARIA, D. B.; OLIVEIRA, P. de. C.; CALDAS, S.; OLIVEIRA, D. A.; SOBRAL, M. E. G.; DUARTE, M. G. R.; MOREIRA, C. P. de. S; SILVA, C. G.; ALMEIDA, V. L. Screening of Brazilian medicinal plants for antiviral activity against rotavirus. Journal Ethnopharmacology, v.141, p. 975-981, 2012.

http://doi.org/10.1016/i.jep.2012.03.031

CORDEIRO, C. H. G.; SACRAMENTO, L. V. S. do.; CORRÊA, M. A.; PIZZOLITTO, A. C.; BAUAB, T. M. Análise farmacológica e atividade antibacteriana de extratos vegetais empregados em formulação para a higiene bucal. Brazilian Journal of Pharmaceutical Sciences, v.42, n.3, 2006.

CORRÊA, M. P. Dicionário das plantas úteis do Brasil e das exóticas cultivadas. Rio de Janeiro: Imprensa Nacional, 1984.

COSTA, M. S.; PEREIRA, M. J. B.; OLIVEIRA, S. S.; SOUZA, P. T.; DALL'OGLIO, E. V.; ALVES, T. C. Anonáceas provocam mortalidade em larvas de Aedes aegypti (Linnaeus, 1762) (Diptera: Culicidae). Brazilian Journal of Bioscience, v.11, n.2, p. 184-190, 2013.

CLEMES, S. M.; ZENI, A. L. B.; KRETZSCHMAR, M. Avaliação química de folhas de plantas medicinais nativas utilizadas no entorno do Parque da Serra do Itajaí (PNSI). Revista Brasileira de Farmacognosia, v.89, n.1, p. 10-12, 2008.

CRUZ, S. A. B. Avaliação da atividade tóxica e do perfil fitoquímico de duas espécies da família Fabaceae: Bowdichia virgilioides Kunth. e Pterodon emarginatus Vogel. 2016. Trabalho de Conclusão de Curso (Licenciatura Plena em Química) - Instituto Federal de Goiás, 2016.

CUNHA, A. P.; ROQUE, O. R. Compostos quinónicos: Antraquinonas e Naftoquinonas. In: CUNHA, A. P. (Coord.). Farmacognosia e fitoquímica. Lisboa: Fundação Calouste Gulbenkian, 2010.

CUSHNIE. T. P.; LAMB, A. J. Antimicrobial activity of flavonoids. International Journal of Antimicrobial Agents, v.26, n.5, p. 343-356, 2005. http://doi.org/10.1016/i.ijantimicag.2005.09.002

DE BONA, A. P.; BATITUCCI, M. C. P.; ANDRADE, M. A.; RIVA, J. A. R.; PERDIGÃO, T. L. Estudo fitoquímico e análise mutagênica das folhas e inflorescências de Erythrina munlugu (Mart. ex Benth.) através do teste de micronúcleo em roedores. Revista Brasileira de Plantas Medicinais, v.14, n.2, p. 344-351, 2012. http://repositorio.ufpa.br/jspui/handle/2011/761 $\underline{4}$

DAVIS, C. C.; ANDERSON, W. R. A filogenia genérico completa de Malpighiaceae inferida a partir de dados de sequências de nucleotídeos e morfologia. American Journal of Botany, v.97, n.12, p. 2031-2048, 2010. 
DUARTE, J. L.; MOTA, L. J. T.; ALMEIDA, S. S. M. S. Análise fitoquímica das folhas de Tabebuia serratifolia (Vahl.) Nicholson (Ipê Amarelo). Revista Estação Científica (UNIFAP), v.4, n.1, p. 33-43, 2014.

EL-AZIZI, M. M.; ATEYA, A. M.; SVOBODA, G. H.; SCHIFF, J. R. P. L.; SLATKIIN, D. J.; KNAPP, J. E. Chemical constituints of Curatella americana (Dilleniaceae). Journal of Pharmaceutical Sciences, v.69, n.3, p. 360-361, 1980. http://doi.org/10.1002/ips.2600690333

GASPI, F. O. G.; FOGLIO, M. A.; CARVALHO, J. E.; MORENO, R. A. Pharmacological activities investigation of crude extracts and fractions from Qualea grandiflora Mart. Journal of Ethnopharmacology, v.107, n.1, p. 19-24, 2006. http://doi.org/10.1016/j.jep.2006.01.023

GODINHO, C. S.; SILVA, C. M.; MENDES, C. S. O.; FERREIRA, P. R. B.; OLIVEIRA, D. A. Estudo fitoquímico de espécies arbóreas do cerrado. Revista Multitexto, v.3, n.1, p. 64-70, 2015.

GOMES, N. M.; MARTINS, R. L.; ALMEIDA, S. S. M. da. S. de. Análise preliminar fitoquímica do extrato bruto das folhas de Nephrolepis pectinata. Revista Estação Científica (UNIFAP), v.7, n.1, p. 77-85, 2017.

GOMES, E. M. C.; PENA, R. C. M.; ALMEIDA, S. S. M. S. Composição fitoquímica e ação fungicida de extratos brutos de Cinnamomum zeylanicum sobre Quambalaria eucalypti. Biota Amazônia, v.6, n.4, p. 54-58, 2016.

http://dx.doi.org/10.18561/2179-

5746/biotaamazonia.v6n4p54-58

GUERRA, M. P.; NODARI, R. O. Biodiversidade: aspectos biológicos, geográficos, legais e éticos. In: SIMÕES, C. M. O. et al. Farmacognosia: da planta ao medicamento. Porto Alegre; Florianópolis: UFRGS/UFSC, 2007.

GUILHION-SIMPLICIO, F.; PEREIRA, M. M. Aspectos químicos e farmacológicos de Byrsonima (Malpighiaceae). Revista Química Nova, v.34, n.6, p. 1032-1041, 2011. http://dx.doi.org/10.1590/S0100$\underline{404222011000600021}$
HENRIQUES, S. V. C.; AMEIDA, S. S. M. S. Identificação do caráter medicinal da espécie Curatella americana por meio das folhas. Revista Estação Científica (UNIFAP), v.3, n.2, p. 89-97, 2013.

HIRUMA-LIMA, C. A.; SANTOS, L. C.; KUSHIMA, H.; PELLIZZON, C. H.; SILVEIRA, G. G.; CASCONCELOS, P. C. P.; VILEGAS, W.; SOUZA BRITO, A. R. M. Qualea grandiflora, a brazilian "cerrado" medicinal plant presents na important antiulcer activity. Journal of Ethnopharmacology, v.104, n. 1-2, p. 207-2014, 2006. http://doi.org/10.1016/j.jep.2005.09.002

JÚNIOR, A. R. C.; GOMES, G. A.; FERREIRA, R. O.; CARVALHO, M. G. Constituintes químicos e atividade antioxidante de folhas e galhos de Eugenia. Química Nova, v.37, n.3, p. 477-482, 2014. http://dx.doi.org/10.5935/0100$\underline{4042.20140079}$

KLOSS, L. C.; ALBINO, A. M.; SOUZA, R. G.; LIMA, R. A. Identificação de classes de metabólitos secundários do extrato etanólico de Piper umbellatum L. (PIPERACEAE). South American Journal of Basic Education, Technical and Technological, v.3, n.2, p. 2446-4821, 2016.

KUSTER, R. M.; ROCHA, L. M. Cumarinas, cromonas e xantonas. In: SIMÕES, C.M.O. et al. (Eds.). Farmacognosia: da planta ao medicamento. 6. ed. Porto Alegre: Editora Universidade/UFRGS, 2010.

LIMA NETO, G. A.; KAFFASHI, S.; LUIZ, W. T.; FERREIRA, W. R.; DIAS DA SILVA, Y. S. A.; PAZIN, G. V.; VIOLANTE, I. M. P. Quantificação de metabólitos secundários e avaliação da atividade antimicrobiana e antioxidante de algumas plantas selecionadas do cerrado de Mato Grosso. Revista Brasileira de Plantas Medicinais, v.17, n.4, supl. III, p. 1069-1077, 2015.

LIMA, R. A.; SILVA, A. C. Identificação das classes de metabólitos secundários no extrato etanólico dos frutos e folhas de Eugenia uniflora L. Revista Eletrônica em Gestão, Educação e Tecnologia Ambiental, v.20, n.1, p. 381-388, 2016. http://dx.doi.org/10.5902/2236117019537

LOPES, J. D. C.; MELLO-SILVA, R. Diversidade e caracterização das Annonaceae do Brasil. Revista Brasileira de Fruticultura, v.36, p. 125-131, 2014. 
MACEDO, F. M. de.; MARTINS, G. T.; RODRIGUES, C. G.; OLIVEIRA, D. A. de. Triagem fitoquímica do barbatimão [Stryphnodendron adstringens (Mart) Coville]. Revista Brasileira de Biociências, v.5, supl.2, p. 1166-1168, 2007.

MENDANHA, D. M.; FERREIRA, H. D.; FELÍCIO, L. P.; SILVA, E. M.; PEREIRA, D. G.; NUNES, W. B.; CARVALHO, S. Modulatory effect of Byrsonima verbascifolia (Malpighiaceae) against damage induced by doxorubicin in somatic cells of Drosophila melanogaster. Genetic and Molecular Research, v.9, n.1, p. 69-77, 2010.

TOLEDO, C. E. M. de; SANTOS, P. R.; DE MELLO, J. C. P.; FILHO, B. P. D.; NAKAMURA, C. V.; UEDANAKAMURA, T. Antifungal properties of crude extracts, fractions, and purified compounds from bark of Curatella americana L. (Dilleniaceae) against Candida species. Evidence-Based Complementary and Alternative Medicine, p. 19, 2015. http://dx.doi.org/10.1155/2015/673962

MAMEDE, M. C. H.; SEBASTIANI, R.; ALMEIDA, R. F.; FRANCENER, A.; AMORIM, A. M. A. 2015. Malpighiaceae. In: Lista de espécies da flora do Brasil. Jardim Botânico do Rio de Janeiro. Available

at http://floradobrasil.jbri.gov.br/jabot/floradobrasi l/FB155

MENDONÇA, R. C.; FELFILI, J. M.; WALTER, B. M. T.; SILVA-JÚNIOR, M. D.; REZENDE, A. V.; FILGUEIRAS, T. D. S; FAGG, C. W. Flora vascular do cerrado: checklist com 12.356 espécies. In: Cerrado: ecologia e flora. Planaltina: Embrapa, 2008. p. 417-1279.

MENEZES, A. C. P. F.; OLIVEIRA FILHO, J. G. de.; CHRISTOFOLI, M.; CASTRO, C. F. de. Atividade antioxidante, conteúdo de fenólicos totais, carotenoides e provitamina A em extratos vegetais do cerrado goiano. Revista Uniciências, v.22, n.1, p. 28-32, 2018.

http://dx.doi.org/10.17921/1415-

$\underline{5141.2018 \mathrm{v} 22 \mathrm{n} 1 \mathrm{p} 2832}$

MENEZES FILHO, A. C. P.; CASTRO, C. F. S. Classes fitoquímicas de metabólitos secundários em extratos etanólicos foliares de espécies do cerrado brasileiro. Revista Saúde e Ciência, v.8, n.1, p. 45-61, 2019.
MICHELETTI, A. C.; ADILSON, B.; LIMA, D. P. de.; HONDA, N. K.; PESSOA, C. do. Ó.; MORAES, M. O. de.; LOTUFO, L. V.; MAGALHÃES, H. I. F.; CARVALHO, N. C. P. Constituintes químicos de Parmotrema lichexanthonicum Eliasaro \& Adler Isolamento, modificações estruturais e avaliação das atividades antibiótica e citotóxica. Revista Química Nova, v.32, n.1, p. 12-20, 2009.

http://dx.doi.org/10.1590/S0100$\underline{40422009000100003}$

MOTA, L. J. T. Estudo químico e biológico das folhas e galhos de Hyptis crenata (Pohl.) ex Benth (Lamiaceae - Lamiles). 2013. 63 f. Dissertação (Mestrado em Ciência da Saúde) Universidade Federal do Amapá, Macapá. 2013.

MOTA, T. H. S.; SOUZA, S. R. de.; SANTOS, A. P.; CUNHA, C. R. M. da. Estudo farmacológico das folhas de Sterculia striata St. Hil. Et. Naid., coletadas em Itapuranga-GO. Revista Eletrônica Faculdade Montes Belos (FMB), v.7, n.1, p. 3468, 2014.

MYERS, N.; MITTERMEIER, R. A.; MITTERMEIER, C. G.; FONSECA, G. A. B.; KENT, J. Biodiversity hotspots for conservation priorities. Nature, v.403, n.6772, p. 853-858, 2000.

http://doi.org/10.1038/35002501

OLIVEIRA, R. M. de.; LIMA, R. A. Prospecção fitoquímica do extrato etanólico de Bauhinia forficata L. e seu potencial candicida. South American Journal of Basic Education, Technical and Technological, v.4, n.1, p. 54-65, 2017.

OLIVEIRA, C. F. de.; OLIVEIRA, V. B.; OLIVEIRA, F. F.; MIGUEL, O. G.; MIGUEL, M. D. Parâmetros de controle de qualidade de Psychotria fractistipula L. B. Sm., Klein \& Delprete (Rubiaceae): umidade, cinzas e prospecção fitoquímica. Revista Visão Acadêmica, v.15, n.4, p. 17-23, 2014.

http://dx.doi.org/10.5380/acd.v15i4.40032

PINHO, L. de.; SOUZA, P. N. S.; SOBRINHO, E. M.; ALMEIDA, A. C. de.; MARTINS, E. R. Atividade antimicrobiana de extratos hidroalcoólicos das folhas de alecrim-pimenta, aroeira, barbatimão, erva baleeira e do farelo da casca de pequi. Revista Ciência Rural, v.42, n.2, p. 326-331, 2012.

QUEIROZ, K. A.; SOUSA, F. F. O. Avaliação da estabilidade de gel cremoso contendo extrato de Curatella americana. In: BRITO, A. U.; DALMÁCIO, 
C. E. C.; SIMÕES, H. C. G. Q. (orgs.). Ciências da saúde: resultados dos projetos de iniciação científica da Universidade Federal do Amapá (2012-2016). 1. ed. Macapá: Editora da Universidade Federal do Amapá, 2017. p. 19-40.

RANDAU, K. P.; FLORÊNCIO, D. C.; FERREIRA, C. P.; XAVIER, H. S. Estudo farmacognóstico de Croton rhamnifolius H. B. K. e Croton rhamnifolioides Pax \& Hoffm. (Euphorbiaceae). Revista Brasileira de Farmacognosia, v.14, n.2, p. 89-96, 2004.

http://dx.doi.org/10.1590/S0102695X2004000200001

RATES, S. M. K.; BRIDI, R. Heterosídeos cardiotônicos. In: SIMÕES, C. M. O. et al. Farmacognosia: da planta ao medicamento. 6. ed. Porto Alegre: Editora Universidade/UFRGS, 2010.

RIO DE JANEIRO. Instituto de Pesquisa Jardim Botânico. Lista de espécies da flora do Brasil. Rio de Janeiro: COPPETEC, 2019. Disponível em: floradobrasil.jbrj.gov.br. Acesso em: 4 ago. 2019.

RODRIGUES, I. M. C.; SOUZA FILHO, A. P. S.; FERREIRA, F. A. Estudo fitoquímico de Senna alata por duas metodologias. Revista Planta Daninha, v.27, n.3, p. 507-513, 2009.

http://alice.cnptia.embrapa.br/alice/handle/doc/ $\underline{658208}$

SALDANHA, A. A.; SOARES, A. C. Compostos químicos e aspectos botânicos, etnobotânicos e farmacológicos da Byrsonima verbascifolia Rich ex. A. Juss. Revista Brasileira de Plantas Medicinais, v.17, n.4, supl. II, p. 1000-1006, 2015.

SCHIRATO, G. V.; MONTEIRO, F. M. F.; SILVA, F. de. O.; FILHO, J. L. de. L; LEÃO, A. M. dos. A. C. Polissacarídeo do Anacardium occidentale L. na fase inflamatória do processo cicatricial de lesões cutâneas. Revista Ciência Rural, v.36, n.1, p. 149154, 2006.

SILVA, R. M.; FARIA, M. T. Caracterização etnobotânica e histoquímica de plantas medicinais utilizadas pelos moradores do bairro carrilho, Goianésia, GO. Revista Enciclopédia Biosfera, C. Cient. Com., v.10, n.19, p. 2807-2829, 2014.

SILVA, N. L. A.; MIRANDA, F. A. A.; CONCEIÇÃO, G. $M$. Triagem fitoquímica de plantas de cerrado, da
Área de Proteção Ambiental Municipal de Inhamum, Caxias, Maranhão. Revista Scientia Plena, v.6, n.2, p. 1-17, 2010.

SILVA, R. S. G.; PEIXOTO, J. C. Acanthaceaes do bioma cerra: identificação dos fitoquímicos das folhas da espécie Justicia thunbergioides (Lindau) Leonard (Acanthaceae) ocorrente no Parque Estadual Serra dos Pireneus, Pirenópolis, GO. FRONTEIRA Revista do Mestrado Multidisciplinar em Sociedade, Tecnologia e Meio Ambiente, v.2, n.1, p. 16-27, 2013.

SIMÕES, C. M. O. et al. Farmacognosia: da planta ao medicamento. 5. ed. Porto Alegre: UFSC, 2004.

SOARES, M. L.; REZENDE, M. H.; FERREIRA, H. D.; ECHALAR, A. D. L. F.; BUSTAMANTE, K. G. L.; BARA, M. T. F.; PAULA, J. R. de. Caracterização farmacognóstica de folhas de Davilla elliptica St.Hil. (Dilleniaceae). Revista Brasileira de Farmacognosia, v.15, n.4, p. 352-360, 2005. http://repositorio.bc.ufg.br/handle/ri/16044

VERDI, L. G.; BRIGHENTE, I. M. C.; PIZZOLATTI, M. G. Gênero Baccharis (Asteraceae): aspectos químicos, econômicos e biológicos. Revista Química Nova, v.28, n.1, p. 85-94, 2005.

http://dx.doi.org/10.1590/S0100$\underline{40422005000100017}$

VILA VERDE, G. M.; PAULA, J. R.; CARNEIRO, D. M. Levantamento etnobotânico das plantas medicinais do Cerrado utilizadas pela população de Mossâmedes (GO). Revista Brasileira de Farmacognosia, v.13, n.1, p. 64-66, 2003. http://dx.doi.org/10.1590/S0102$\underline{695 \times 2003000300024}$

VIZZOTTO, M.; KROLOW, A. C.; WEBER, G. E. B. Metabólitos secundários encontrados em plantas e sua importância. Pelotas: Embrapa, 2010. 16 p. (Embrapa Clima Temperado. Documentos, 316).

XAVIER, M. N.; ALVES, C. C. F.; CAZAL, C. de. M.; SANTOS, N. H. Chemical composition of the volatile oil of Cardiopetalum calophyllum collected in the Cerrado area. Ciência Rural, v.46, n.5, p. 937-942, 2016.

http://dx.doi.org/10.1590/0103-8478cr20150371

ZAPPI, D. C.; FILARDI, F. L. R.; LEITMAN, P.; SOUZA, V. C.; WALTER, B. M. T.; PIRANI, J. R. Growing knowledge: an overview of seed plant 
diversity in Brazil. Rodriguesia, v.66, n.4, p.1085-

1113, 2015.

http://10.1590/2175-7860201566411 